\title{
A KEY TO THE GENERA AND SUBGENERA OF STINGLESS BEES IN INDONESIA (HYMENOPTERA: APIDAE)
}

\author{
Michael S. Engel $^{* 1,2}$, Sih Kahono ${ }^{3}$ and Djunijanti Peggie ${ }^{3}$ \\ ${ }^{1}$ Division of Entomology, Natural History Museum, and Department of Ecology \& \\ Evolutionary Biology, 1501 Crestline Drive - Suite 140, University of Kansas, Lawrence, \\ Kansas 66045, USA \\ ${ }^{2}$ Division of Invertebrate Zoology, American Museum of Natural History, \\ Central Park West at $79^{\text {th }}$ Street, New York, New York 10024, USA \\ ${ }^{3}$ Zoology Division (Museum Zoologicum Bogoriense), Research Center for Biology, \\ Indonesian Institute of Sciences, Jl. Raya Jakarta-Bogor Km 46, Cibinong, Bogor 16911, Indonesia \\ *Corresponding author: msengel@ku.edu
}

Received: 3 October 2018; Accepted: 7 December 2018

\begin{abstract}
Indonesia harbors the greatest diversity of social bees in all of Asia, particularly of the stingless bees (Apidae: Apinae: Meliponini). Presently, 46 species of stingless bees are known across Indonesia although records are not comprehensive and additional diversity is likely present across the region. All of the known Asiatic genera of Meliponini occur in Indonesia, making this region a critical center of modern stingless bee biodiversity in Asia. Presented here is an illustrated key to the genera and subgenera of Indonesian stingless bees, as an aid to the general identification, study, and conservation of these critical pollinators.
\end{abstract}

Keywords: Apoidea, biodiversity, identification keys, Meliponini, stingless bees

\section{INTRODUCTION}

Bees are critical pollinators in natural and agricultural ecosystems throughout the world, and while most of the 20,000 described species are solitary, there are highly conspicuous species that are social and live in large perennial colonies (Michener, 2007). The most familiar of these social bees are the honey bees (Apini: Apis Linnaeus), of which Apis mellifera Linnaeus and $A$. cerana Fabricius are the most widely distributed and are frequently managed in apiculture. Indonesia is unique among most countries in that more species of Apis occur across the islands than in any other region, with five of the seven known species found within the country (Engel, 1999, 2012; Radloff et al., 2011). The similarly social stingless bees (Meliponini) are globally more diverse than Apis, with approximately 500 species, and also store food as honey which can be exploited sustainably by humans. In many areas of the world, meliponiculture, or the management of meliponine colonies (Nogueiro-Neto, 1953; Cortopassi-Laurino et al., 2006; Heard, 2016), has developed rapidly and spawned major industries as well as profited indigenous people who often have historical and important cultural practices associated with stingless bees (Ayala et al., 2013).

Presently, 46 species of stingless bees are recorded across Indonesia, with most of these occurring on Sumatra and Kalimantan (Kahono et al., 2018), although sampling bias towards the larger and more extensively inhabited islands obscures the true patterns of distribution and diversity. Admittedly, more extensive sampling is needed in more remote areas and bordering islands of Sumatra and Kalimantan, but it is even more urgent to 
undertake bee surveys on other islands. Aside from continued exploration of Sulawesi, Timor, and Papua, considerable more work is needed throughout the Lesser Sunda Islands and Maluku, particularly Halmahera, Bacan, Sula Islands, Obi, Buru, Seram, Aru Islands, Barat Daya Islands, and Tanimbar Islands. It is assured that additional species will be added to the total Indonesian fauna once these areas are more adequately sampled (Fig. 1). Once adequate sampling from these islands is completed and taxonomic work is undertaken, it will be possible to produce taxonomic revisions and the associated illustrated keys for the identification of all of Indonesia's species of stingless bees, as well as guides to the other genera of the rich fauna of native bees (e.g., sweat bees, carpenter bees, resin bees, leaf-cutter bees). In addition, the nests and forage resources for the species in these areas are in need of study, alongside any indigenous and traditional uses and knowledge of the bees. Indeed, indigenous knowledge has proved vital in the understanding of local stingless bee faunas as well as supporting sustainable systems whereby local people can benefit culturally and financially (e.g., such systems are greatly advocated for in Central and South America: see Ayala et al., 2013 for examples from Mexico). As of yet, such knowledge has not been extensively documented and reviewed for Indonesia. As more information is recorded and published on the biology and uses of these bees, manuals suitable for the more uniform application and development of meliponiculture across Indonesia could be produced, either for local conditions and species or species-specific manuals. Unfortunately, the basic understanding of the diversity and distributions of the stingless bees on many islands is rudimentary to entirely absent, and there are limited resources for the identification of these bees, which hinders further progress.

The purpose of the present contribution is to provide a regionally accessible key to genera and subgenera of Indonesian stingless bees, reflecting the newly adopted classification for the group (Rasmussen et al., 2017). This key is meant to aid Indonesian researchers in the study of the local melittological fauna and to direct field expeditions. It is hoped that by providing this initial introduction to the fauna, further sampling might be encouraged which will ultimately permit reviews of individual genera for Indonesia and faunal treatments for given provinces and islands and then allow researchers the means to more thoroughly explore the natural history, pollination biology, and interactions with indigenous people of these bee species.

\section{MATERIALS AND METHODS}

The key to genera is augmented from that developed by Engel and presented recently in Rasmussen et al. (2017), while the key to subgenera of Heterotrigona is modified from that of Engel \& Rasmussen (2017). Specimens of representative species of all Asiatic and 
Engel et al.: A key to the genera and subgenera of stingless bees in Indonesia ....

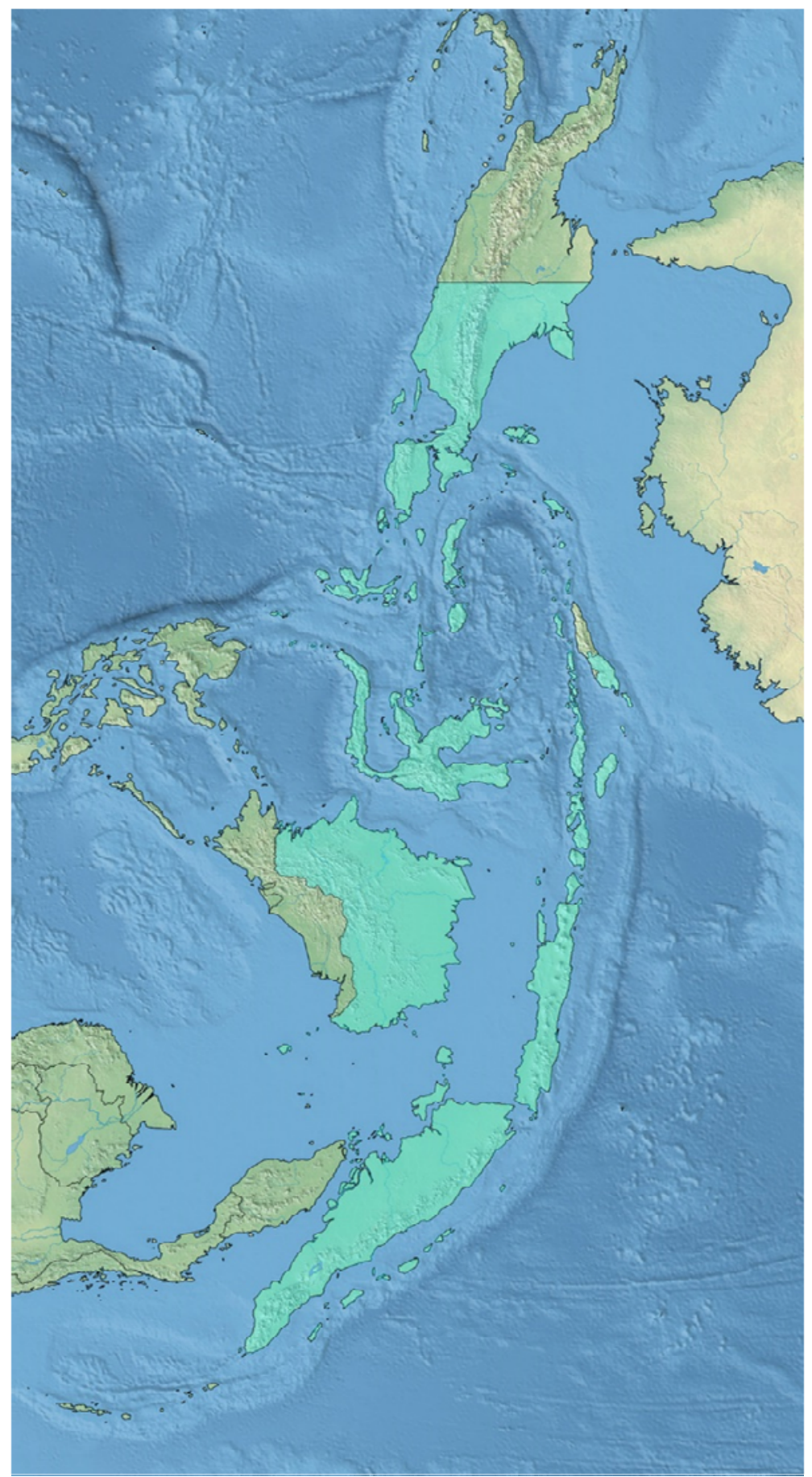

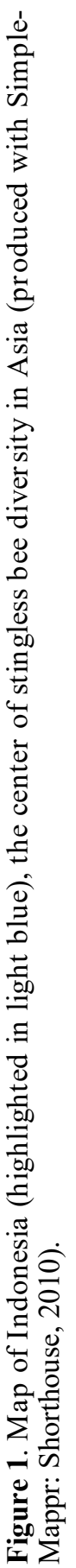


Australian genera and subgenera of Meliponini were examined by M.S. Engel from the collections of the Division of Invertebrate Zoology, American Museum of Natural History, New York (AMNH), the Division of Entomology, University of Kansas Natural History Museum, Lawrence (SEMC), and the Zoology Division (Museum Zoologicum Bogoriense), Research Center for Biology, Indonesian Institute of Sciences (LIPI). The materials were used in the construction of the original keys, for testing the keys, and for the production of figures. The morphological terminology used in the keys is adapted from Engel (2001) and Michener (2007), with terminology for the stages of vein reduction following those proposed by Mason (1986) and the lettering of vein abscissae following that presented by Engel \& Rasmussen (2017) and Rasmussen et al. (2017). Microphotography was undertaken with an Infinity K-2 long-distance lens attached to a Canon EOS 7 digital camera.

\section{RESULTS}

\section{Summary of Indonesian taxa}

In total, 10 genera and a further six subgenera (not including nominate subgenera) of stingless bees are presently recorded in collections from Indonesia (Table 1) (Kahono et al., 2018; pers. obs.). One subgenus of Homotrigona s.l. is likely to be found in Kalimantan, but as of yet, no Indonesian record is available. Homotrigona (Odontotrigona) haematoptera (Cockerell) is known from northern Borneo (Sarawak, Brunei, Sabah), and assuredly will be found in bordering areas of Kalimantan once more extensive surveys are undertaken. In total, at least 46 species of stingless bees are found across Indonesia, more than any other region of the Eastern Hemisphere (Kahono et al., 2018). At present, the largest concentration of records are from Sumatra and Java, followed by Kalimantan and Sulawesi. Scattered records and as-of-yet undescribed species are found in collections for the remaining islands of Indonesia. Once more extensive surveys of the fauna from the eastern half of Indonesia have been completed, then a comprehensive faunal revision and monograph to the species can be completed.

\section{Systematics}

Stingless bees belong to the corbiculate bee tribe Meliponini (Michener, 2007) and can be distinguished from other social corbiculate bees by the following combination of morphological traits: reduction of distal forewing venation; presence of jugal lobe in the hindwing; reduction of sting apparatus; loss of outer mandibular grooves; absence of metatibial spurs; absence of auricle; and absence of inner ramus on pretarsal claws (ungues simple) (Engel, 2001; Michener, 2007). 
Table 1. Classification of Indonesian stingless bee (Meliponini) genera and subgenera as recognized by Rasmussen et al. (2017). The subgenus Odontotrigona (Homotrigona) is not yet recorded from Indonesia, and is therefore not currently listed, but occurs in neighboring areas of Borneo (Sarawak, Sabah, Brunei), and is expected to be discovered in Kalimantan. For a tabulation of Indonesian species, refer to Kahono et al. (2018)

\begin{tabular}{lc}
\hline \multicolumn{1}{c}{ Taxon } & Number of known species (Number of Indonesian species) \\
\hline Genus Austroplebeia Moure, 1961 & $5(1)$ \\
Genus Geniotrigona Moure, 1961 & $2(2)$ \\
Genus Heterotrigona Schwarz, 1939 & $3(2)$ \\
Subgenus Heterotrigona Schwarz, 1939 & $5(5)$ \\
Subgenus Platytrigona Moure, 1961 & $2(1)$ \\
Subgenus Sahulotrigona Engel \& Rasmussen, 2017 & \\
Subgenus Sundatrigona Inoue \& Sakagami, 1993 2 (2) & $5(3)$ \\
Genus Homotrigona Moure, 1961 & $4(3)$ \\
Subgenus Tetrigona Moure, 1961 & $1(1)$ \\
Subgenus Homotrigona Moure, 1961 & $12(6)$ \\
Subgenus Lophotrigona Moure, 1961 & $3(1)$ \\
Genus Lepidotrigona Schwarz, 1939 Lisotrigona Moure, 1961 & $1(1)$ \\
Genus Papuatrigona Michener \& Sakagami, 1990 & $1(1)$ \\
Genus Pariotrigona Moure, 1961 & \\
Genus Tetragonula Moure, 1961 & $31(12)$ \\
Subgenus Tetragonula Moure, 1961 & $4(3)$ \\
Subgenus Tetragonilla Moure, 1961 & $1(1)$ \\
Genus Wallacetrigona Engel \& Rasmussen, 2017 &
\end{tabular}

\section{Key to Indonesian Genera of Meliponini (based on worker caste)}

1. Forewing length less than $3 \mathrm{~mm}$, wing venation greatly reduced (Fig. 2A) and posterior margin of metatibia without plumose setae; hind wing without closed cells, veins closing radial and cubital cells, if visible at all, clear and unpigmented (spectral) (Fig. 2A); forewing with 2Rs and 1rs-m almost always completely absent, thus without indication of submarginal cells; at least distal part of second cubital cell of forewing undefined or defined completely by unpigmented spectral vein traces (i.e., at least $2 \mathrm{Cu}$ and $3 \mathrm{Cu}$ absent or spectral); vein $\mathrm{M}$ of forewing terminating without bend at about position of anterior end of $1 \mathrm{~m}-\mathrm{cu}$ which, however, is absent (i.e., 3M lacking) (Fig. 2A) 2

Forewing length typically over $4 \mathrm{~mm}$, wing venation typically not greatly reduced for Meliponini, but if minute and with some wing reduction, then posterior margin of metatibia with plumose setae intermixed with simple setae; hind wing typically with radial and cubital cells closed by at least weakly brownish nebulous veins; forewing with one or two submarginal cells usually weakly indicated by nebulous traces of 2Rs and 1rs-m (Figs. 2B, 2C), first submarginal cell usually recognizable; second cubital cell of forewing completely indicated by at least faint nebulous veins (i.e., $2 \mathrm{Cu}$ present); vein $\mathrm{M}$ of forewing usually extending at least slightly beyond position of $1 \mathrm{~m}$-cu and angular at apex of tubular portion of vein (i.e., 3M present) (Fig. 2B), the stub of which is usually at least faintly visible 
2. Malar space shorter than flagellar diameter (Fig. 3A); inner margins of compound eyes converging below; worker gonostylus with many minute setae, in addition to setae along outer and distal margins (Sumatra) Lisotrigona Moure

- Malar space almost one-fifth as long as compound eye (Fig. 3B), much longer than flagellar diameter; inner margins of compound eyes nearly parallel; worker gonostylus with setae but without minute setae (Sumatra)

Pariotrigona Moure

3. Mesosoma and usually head without distinct maculation; inner surface of metatibia with strong longitudinal keirotrichiate ridge above which is a broad, depressed shining marginal area

Mesoscutellum and usually face and mesoscutum with well-developed yellow maculation (Figs. 3C, 3E, 3F); inner surface of metatibia with keirotrichiate area broad, nearly reaching posterior margin of metatibia (Figs. 8D, 8E) (West Papua)

Austroplebeia Moure

4. Setae along posterior margin of worker metatibia (Fig. 4A) and males entirely simple, or some plumose only on apical one-fifth or one-sixth of margin; keirotrichiate median zone of inner surface of metatibia separated from shining posterior marginal zone by gentle slope (gentle clivulus) 5 Setae along posterior margin of worker metatibia and some males partly plumose; elevated keirotrichiate median zone of inner surface of metatibia separated from shining posterior marginal zone by abrupt slope (abrupt clivulus) .6

5. Mesoscutum margined with whitish, densely plumose, scale-like setae (Fig. 4B); head and mesosoma dull, with minute close punctures; propodeal dorsum finely reticulate (Fig. 5A); posterior margin of worker metatibia without plumose setae (Sumatra, Java, Kalimantan) Lepidotrigona Moure Mesoscutum without conspicuous plumose setae (Fig. 4D); head and mesosoma shining, although with minute, rather close punctures; propodeal dorsum smooth, shining; posterior margin of worker metatibia with plumose setae among bristles on apical one-fifth or one-sixth of margin (West Papua)

Papuatrigona Michener \& Sakagami

6. Mesoscutellum short, only slightly projecting over metanotum (best seen in profile: Figs. 5C, 9C); malar area variable, typically as long as diameter of diameter of third flagellomere or greater but sometimes approximately $0.5-0.75 \times$ diameter of third flagellomere; vein $\mathrm{M}$ of forewing bent at trace of $1 \mathrm{~m}$-cu (Fig. 2B), sometimes present only as minute stub beyond bend 7

- Mesoscutellum well projected posteriorly, extending over propodeum as far as posterior propodeal angle (change in slope between basal area and posterior surface) 
(best seen in profile: Fig. 5D); malar area linear or at least narrower than $0.5 \times$ diameter of third flagellomere; vein $\mathrm{M}$ of forewing straight and ending at or shortly after 1m-cu (Figs. 2C, 11A, 11B) (refer to key to subgenera for distribution) Tetragonula Moure, s.l.

7. Malar space less than $2 \times$ diameter of third flagellomere ....................................... 8

Malar space $2 \times$ or greater diameter of third flagellomere ....................................... 9

8. Mandible unidentate or bidentate, teeth small (Figs. 6A, 6C) (refer to key to subgenera for distribution) Heterotrigona Schwarz, s.l.

- Mandible bidentate, teeth large, deeply incised, i.e., interdental spaces deep (Figs. $6 \mathrm{~B}, 10 \mathrm{~B})$ (refer to key to subgenera for distribution) Homotrigona Moure, s.l.

9. Vertex with deep depression and elevated ridge rising above level of ocelli (Fig. 7B), posteriorly without deep, concave, medial notch; mesoscutum with dense covering of short, plumose setae amid scattered erect, black setae; apical metasomal terga with dense, long, apically plumose setae amid erect, black setae, with plumose setae at least as long as black setae; keirotrichiate zone of metatibial inner surface narrower than posterior glabrate zone, and greater than length of apical glabrate zone (Figs. 8B, 8C) (Sumatra, Kalimantan) Geniotrigona Moure Vertex without strongly elevated ridge (Fig. 7D), with faint transverse depression and ridge posterior to ocelli, posteriorly with deep, concave medial incision (Fig. 7E); mesoscutum without dense covering of short, plumose setae amid scattered erect, black setae; apical metasomal terga with short, scattered plumose setae amid longer, erect, black setae; keirotrichiate zone of metatibial inner surface about as broad as or slightly broader than posterior glabrate zone, and subequal to length of apical glabrate zone (Sulawesi) .Wallacetrigona Engel \& Rasmussen

\section{Key to Subgenera of Heterotrigona}

1. Basal area of propodeum largely or entirely glabrous, at most with wispy apicolateral patches of setae 2 Basal area of propodeum entirely pubescent (Fig. 5B), or with a small medial glabrous patch [in Heterotrigona hobbyi (Schwarz)] (Maluku: Kei Islands; West Papua, Papua) Platytrigona Moure

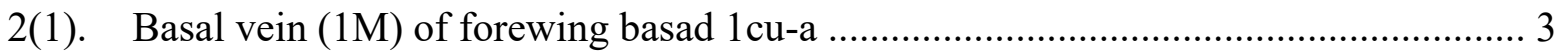

- Basal vein (1M) of forewing distad 1cu-a (Irian Jaya: Papua) ........................................................Sahulotrigona Engel \& Rasmussen 
3(2). Posterior glabrate zone of metatibial inner surface apically broader than keirotrichiate zone; forewing length more than $5.5 \mathrm{~mm}$ (Sumatra, Java, Kalimantan) Heterotrigona Schwarz, s.str.

- Posterior glabrate zone of metatibial inner surface apically narrower than or at most as broad as keirotrichiate zone; forewing length less than $6.0 \mathrm{~mm}$ (Sumatra) Sundatrigona Inoue \& Sakagami

\section{Key to Subgenera of Homotrigona}

1. Basal sericeous area of metabasitarsus present; clypeus approximately $2 \times$ broader than long

Basal sericeous area of metabasitarsus absent; clypeus short, at least $2.5 \times$ broader than long (Sumatra, Kalimantan) Homotrigona Moure, s.str.

2(1). Basal area of propodeum smooth and glabrous; vertex not elevated posterior to ocelli 3

- Basal area of propodeum pubescent (Figs. 5B, 10C); vertex elevated posterior to ocelli (Fig. 10D) (Sumatra, Kalimantan) Lophotrigona Moure

3(2). Malar space as long as flagellar diameter; clypeus with a transverse row of erect setae along apical margin; metabasitarsus $2 \times$ as long as wide (Sumatra, Kalimantan, West Timor) Tetrigona Moure Malar space about as long as $1.5 \times$ flagellar diameter; clypeus with erect black setae scattered over entire surface; metabasitarsus less than $1.5 \times$ as long as wide (not yet recorded from Indonesia but likely to be found across Kalimantan). 

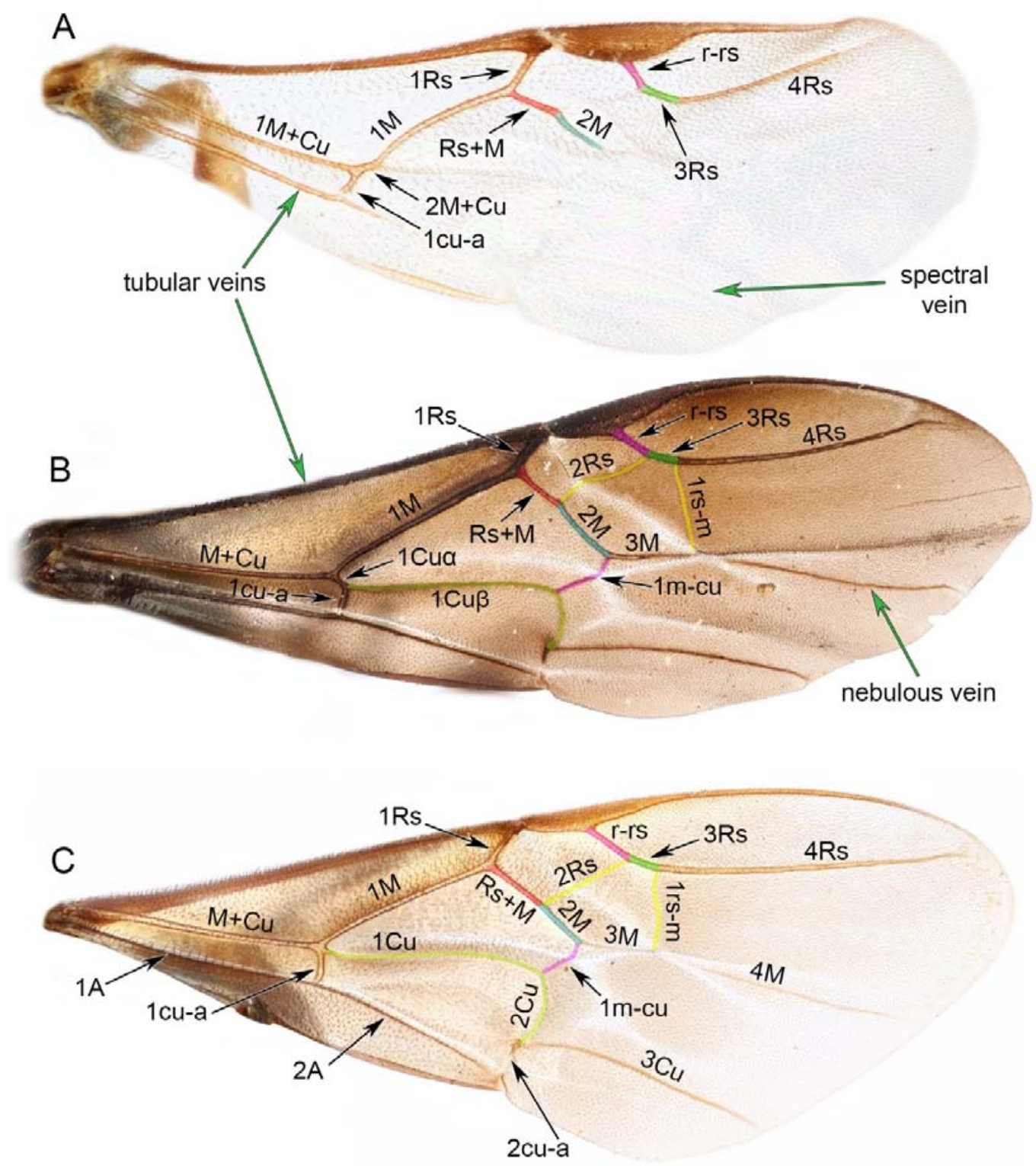

Figure 2. Representative for ewings of Meliponini (reproduced and modified with permission from Rasmussen et al. 2017), with major veins and crossveins labeled and examples of different forms of vein development indicated by green arrows. A. Lisotrigona carpenteri Engel. B. Wallacetrigona incisa (Sakagami \& Inoue). C. Tetragonula (Tetragonilla) atripes (Smith). 

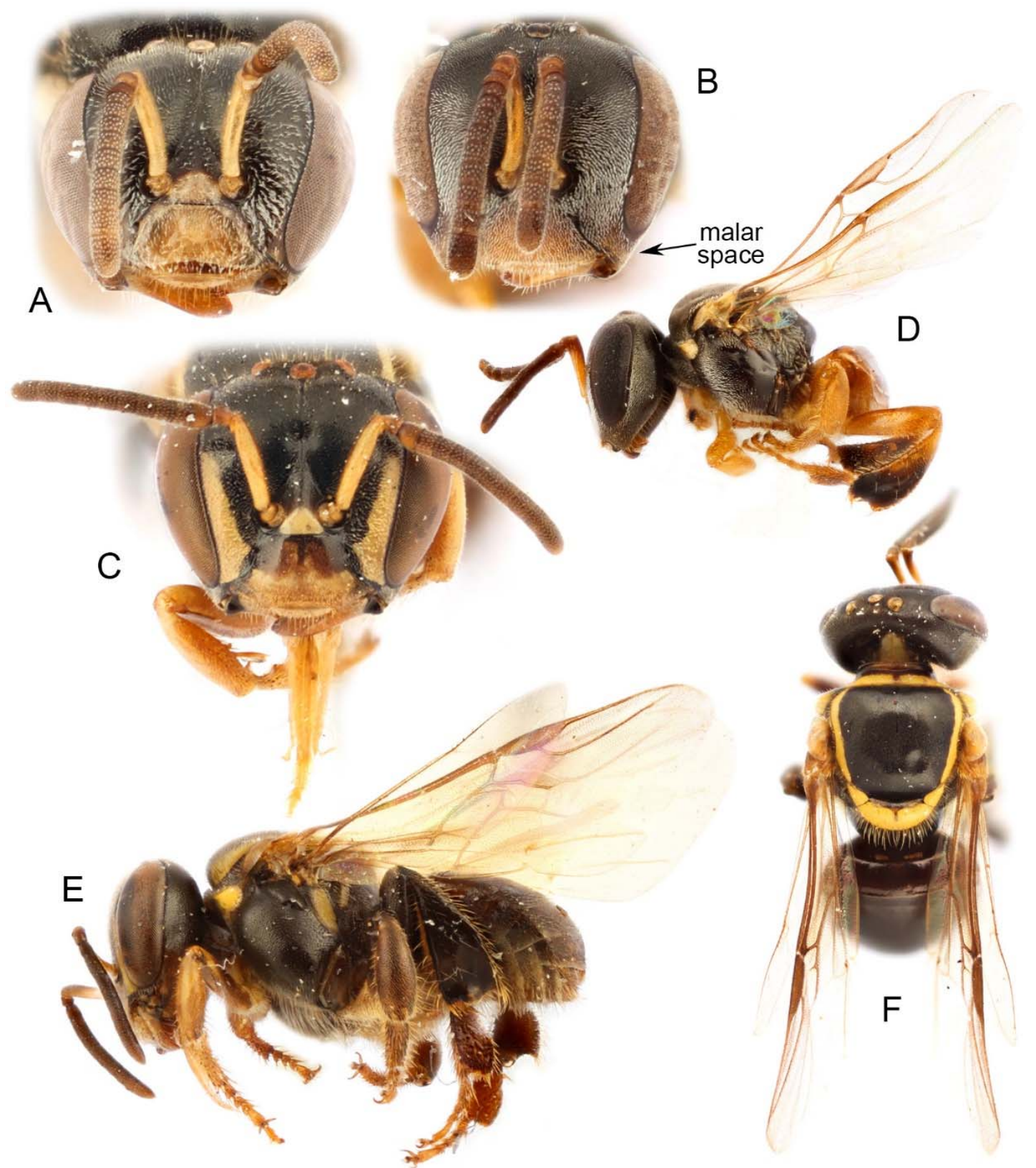

Figure 3. Morphological details of workers of the genera Lisotrigona Moure, Pariotrigona Moure, and Austroplebeia Moure (A, B, C, and F reproduced and modified with permission from Rasmussen et al. 2017). A. Facial view of Lisotrigona carpenteri Engel. B. Facial view of Pariotrigona pendleburyi (Schwarz). C. Facial view of Austroplebeia cincta (Mocsáry). D. Lateral habitus of $P$. pendleburyi. E. Lateral habitus of $A$. cincta. F. Dorsal habitus of $A$. cincta. 


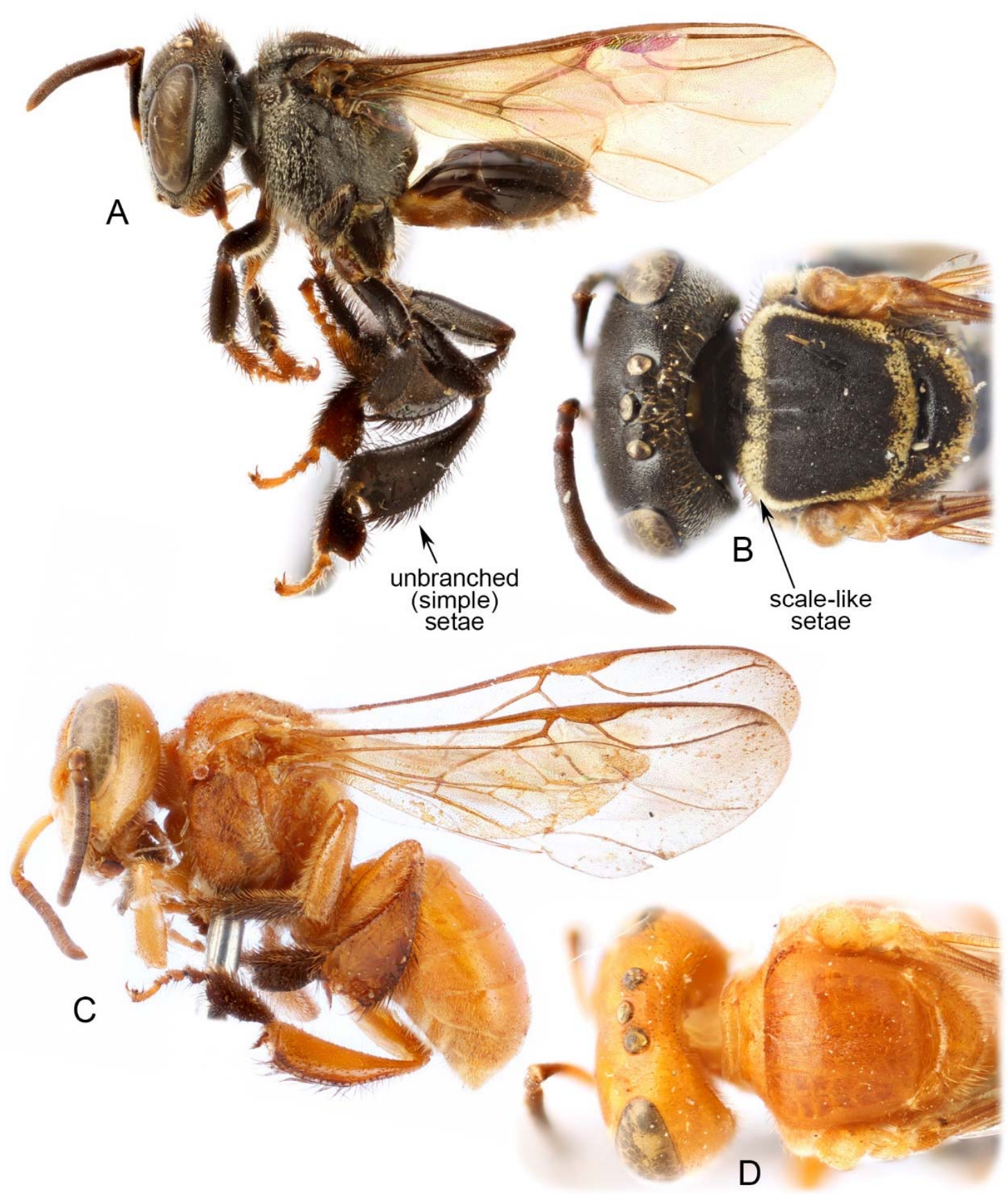

Figure 4. Morphological details of workers of the genera Lepidotrigona Schwarz and Papuatrigona Michener \& Sakagami (B and D reproduced and modified with permission from Rasmussen et al. 2017). A. Lateral habitus of Lepidotrigona sp. B. Dorsal view of head and mesosoma of L. terminata (Smith). C. Lateral habitus of Papuatrigona genalis (Friese). D. Dorsal view of head and mesosoma of P. genalis. 

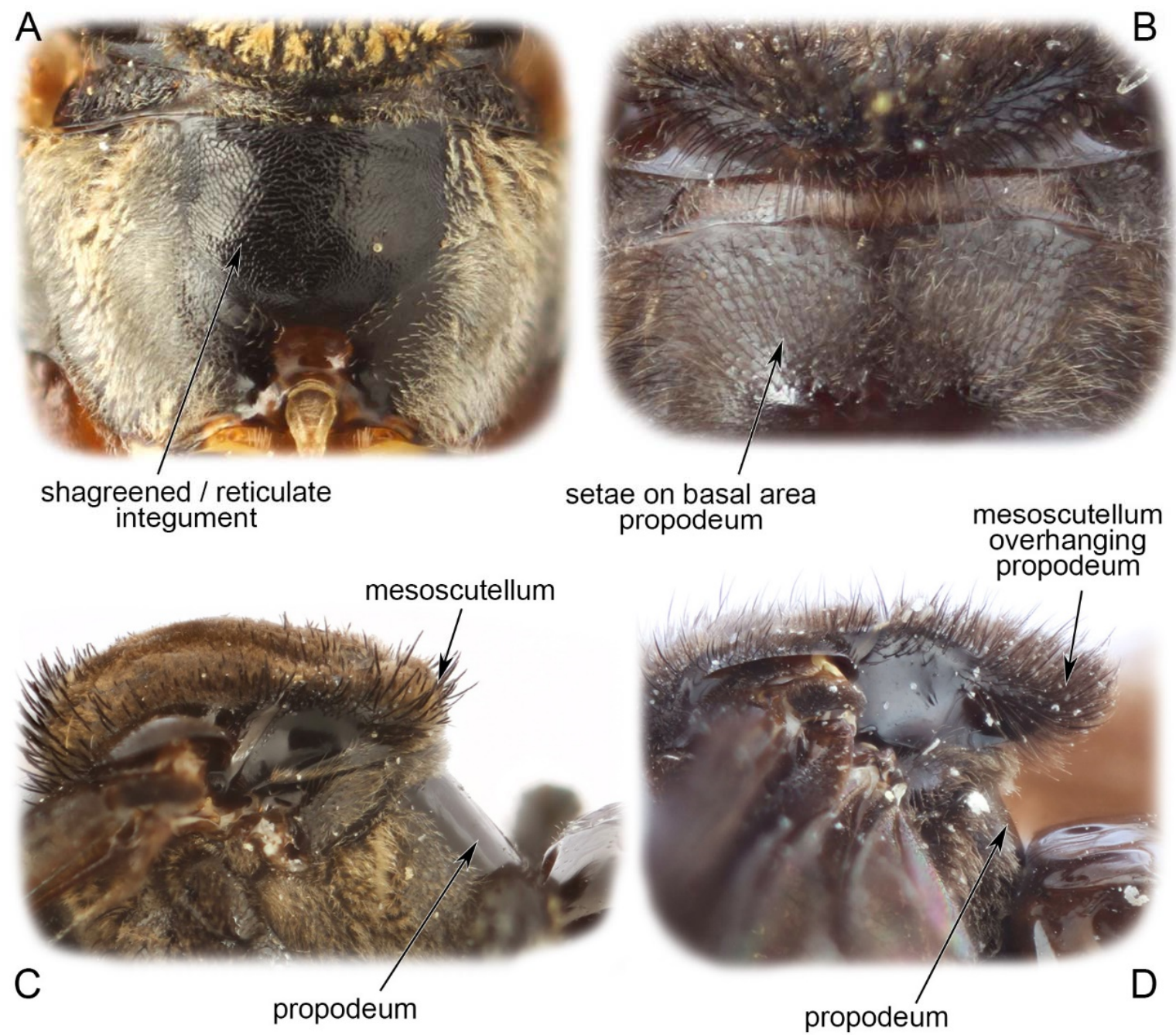

Figure 5. Morphological details of the mesosoma of stingless bee workers (reproduced and modified with permission from Rasmussen et al. 2017). A. Propodeal basal surface of Lepidotrigona terminata (Smith). B. Propodeal basal surface of Homotrigona (Lophotrigona) canifrons (Smith). C. Profile of upper mesosoma of Heterotrigona (Heterotrigona) itama (Cockerell). D. Profile of upper mesosoma of Tetragonula (Tetragonilla) collina (Smith). 

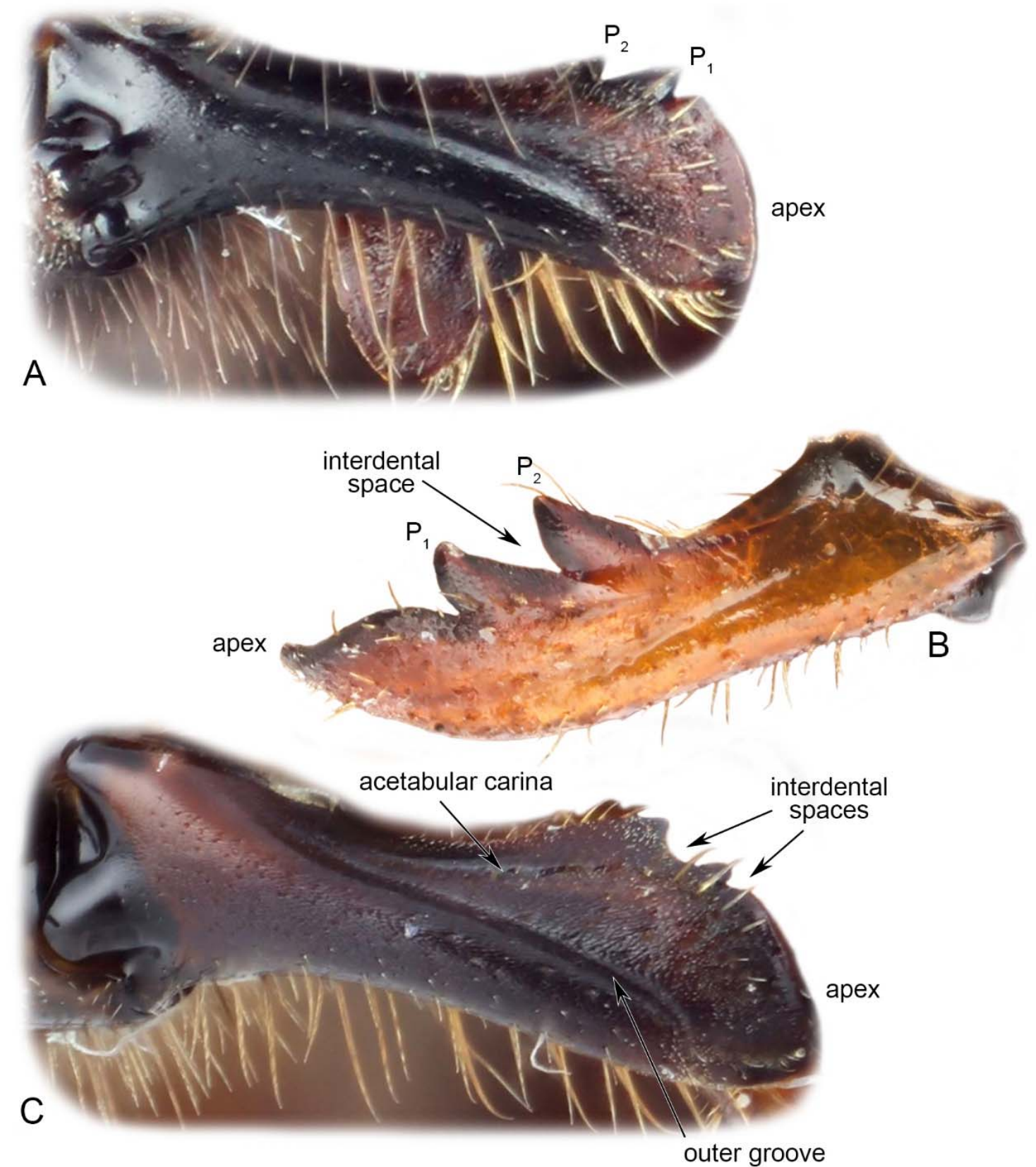

Figure 6. Mandibles of representative stingless bee workers (reproduced and modified with permission from Rasmussen et al. 2017), preapical teeth denoted by $\mathrm{P}_{1}$ and $\mathrm{P}_{2}$. A. Wallacetrigona incisa (Sakagami \& Inoue). B. Homotrigona (Homotrigona) fimbriata (Smith). C. Geniotrigona thoracica (Smith). 


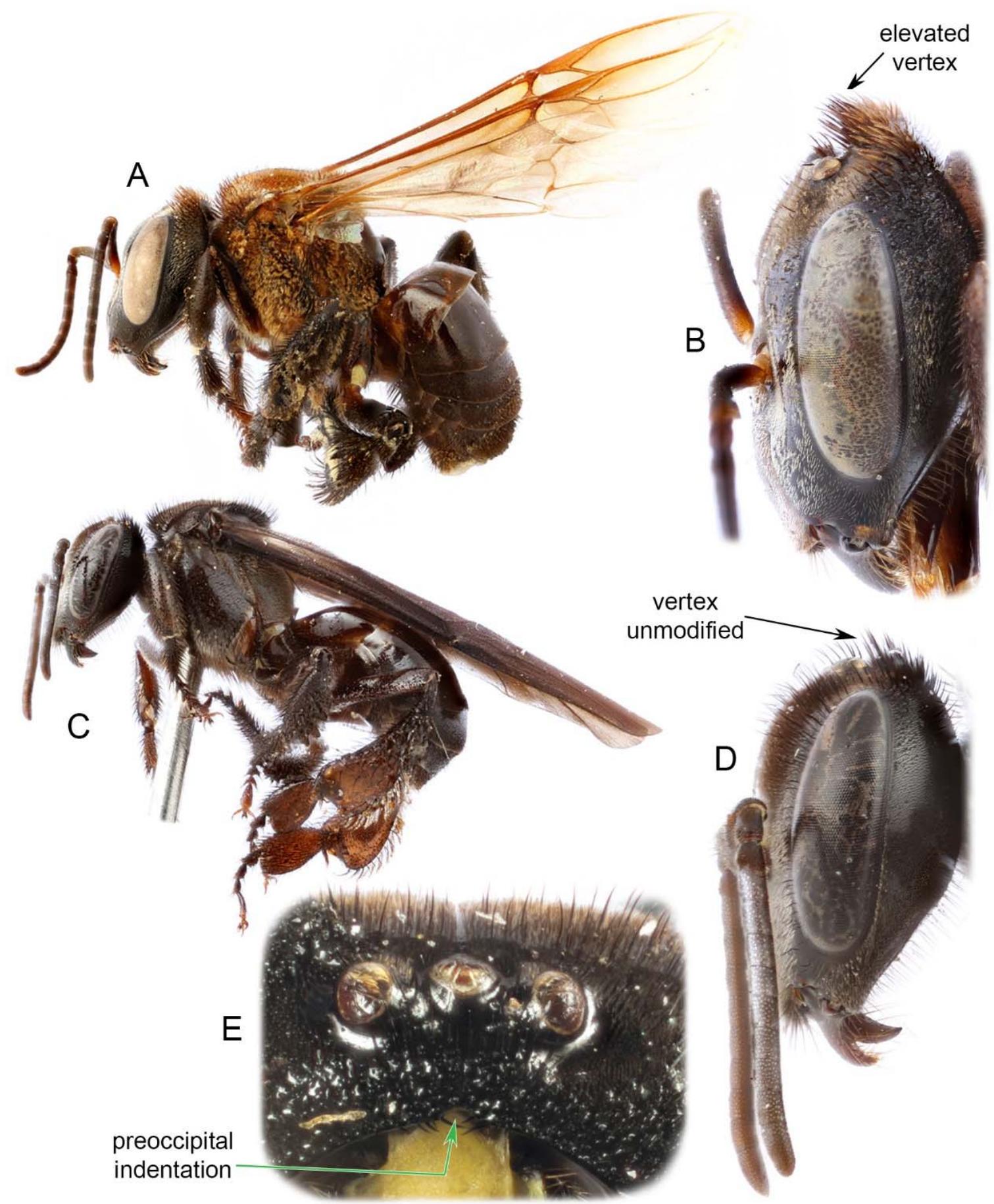

Figure 7. Morphological details of workers of Geniotrigona Moure and Wallacetrigona Engel \& Rasmussen (reproduced and modified with permission from Rasmussen et al. 2017). A. Lateral habitus of Geniotrigona thoracica (Smith). B. Profile of head of G. thoracica. C. Lateral habitus of Wallacetrigona incisa (Sakagami \& Inoue). D. Profile of head of W. incisa. E. Vertex of W. incisa. 


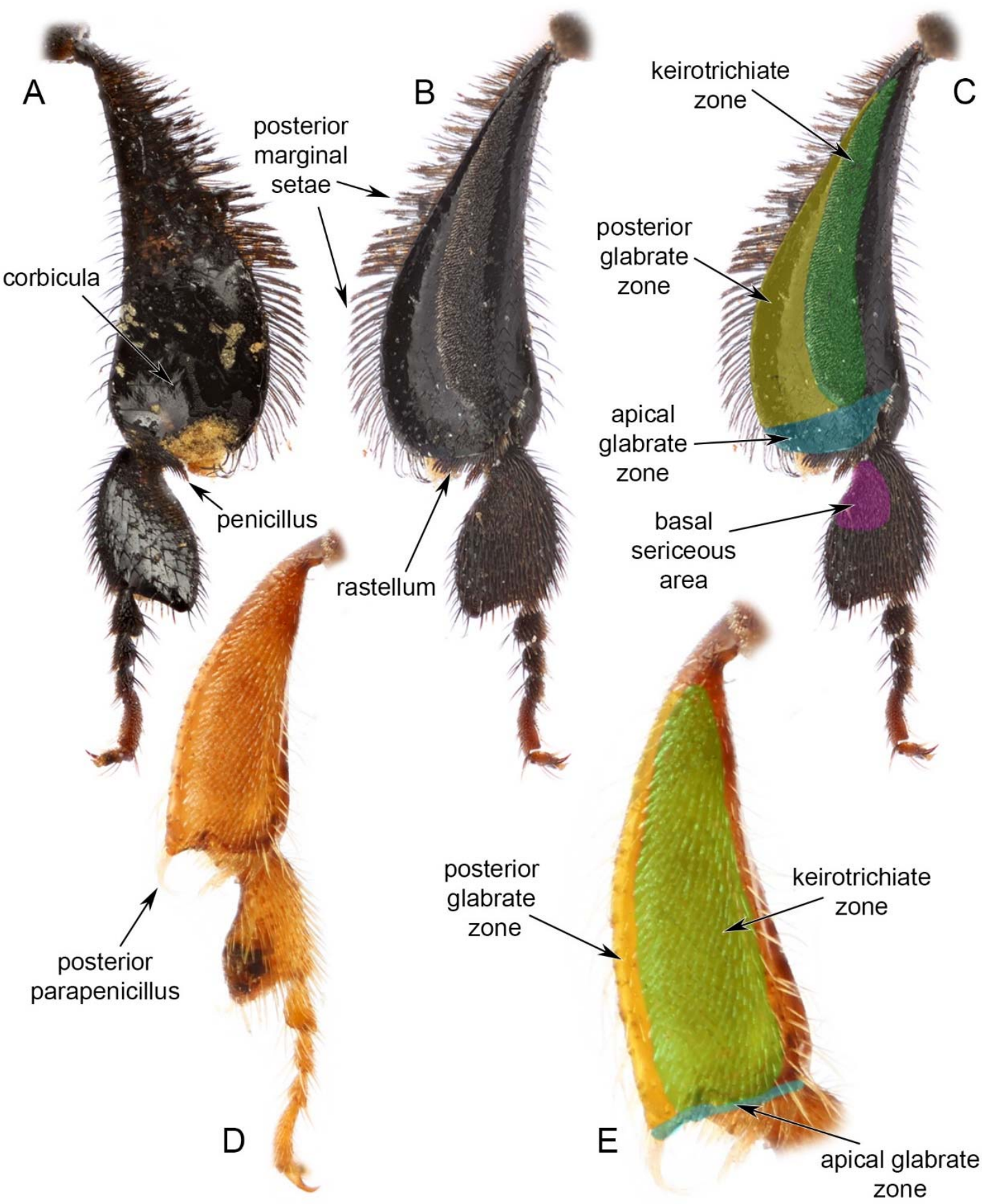

Figure 8. Morphological details of worker legs (reproduced and modified with permission from Rasmussen et al. 2017). A. Outer surface of metatibia, metabasitarsus, and metapretarsus of Geniotrigona thoracica (Smith). B. Inner surface of metatibia, metabasitarsus, and metapretarsus of G. thoracica (Smith). C. Inner surface from B with pertinent areas labeled and colored (green = keirotrichiate zone; yellow = posterior glabrate zone; red = lower glabrate zone blending into anterior surface; pink = basal sericeous area). D. Inner surface of metatibia, metabasitarsus, and metapretarsus of Austroplebeia cincta (Mocsáry). E. Inner surface of metatibia of $A$. cincta with pertinent areas colored and labeled. 

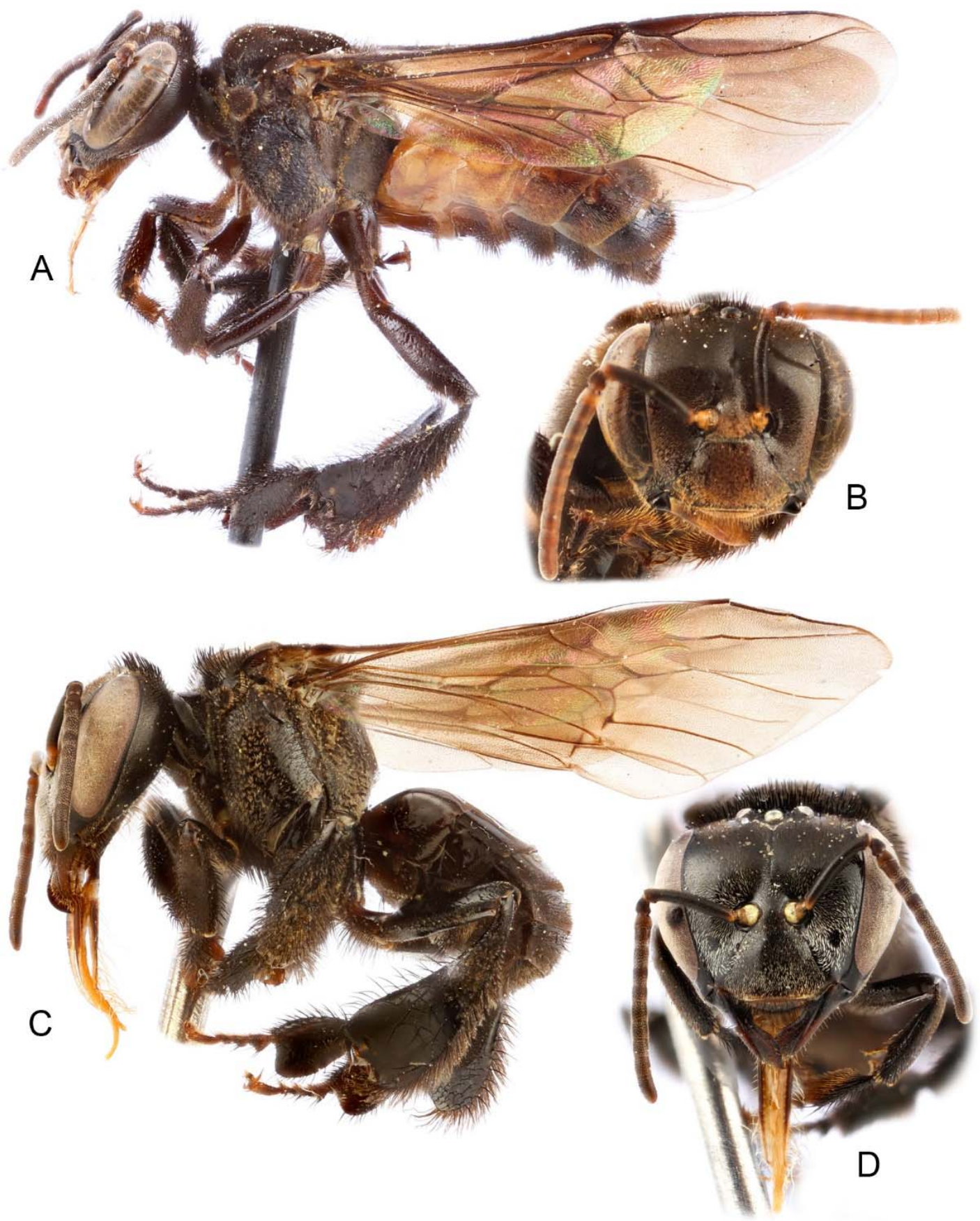

Figure 9. Morphological details of workers of Heterotrigona Schwarz. A. Lateral habitus of Heterotrigona (Platytrigona) flaviventris (Friese). B. Facial view of $H$. (P.) flaviventris. C. Lateral habitus of $H$. (Heterotrigona) itama (Cockerell). D. Facial view of H. (H.) itama. 


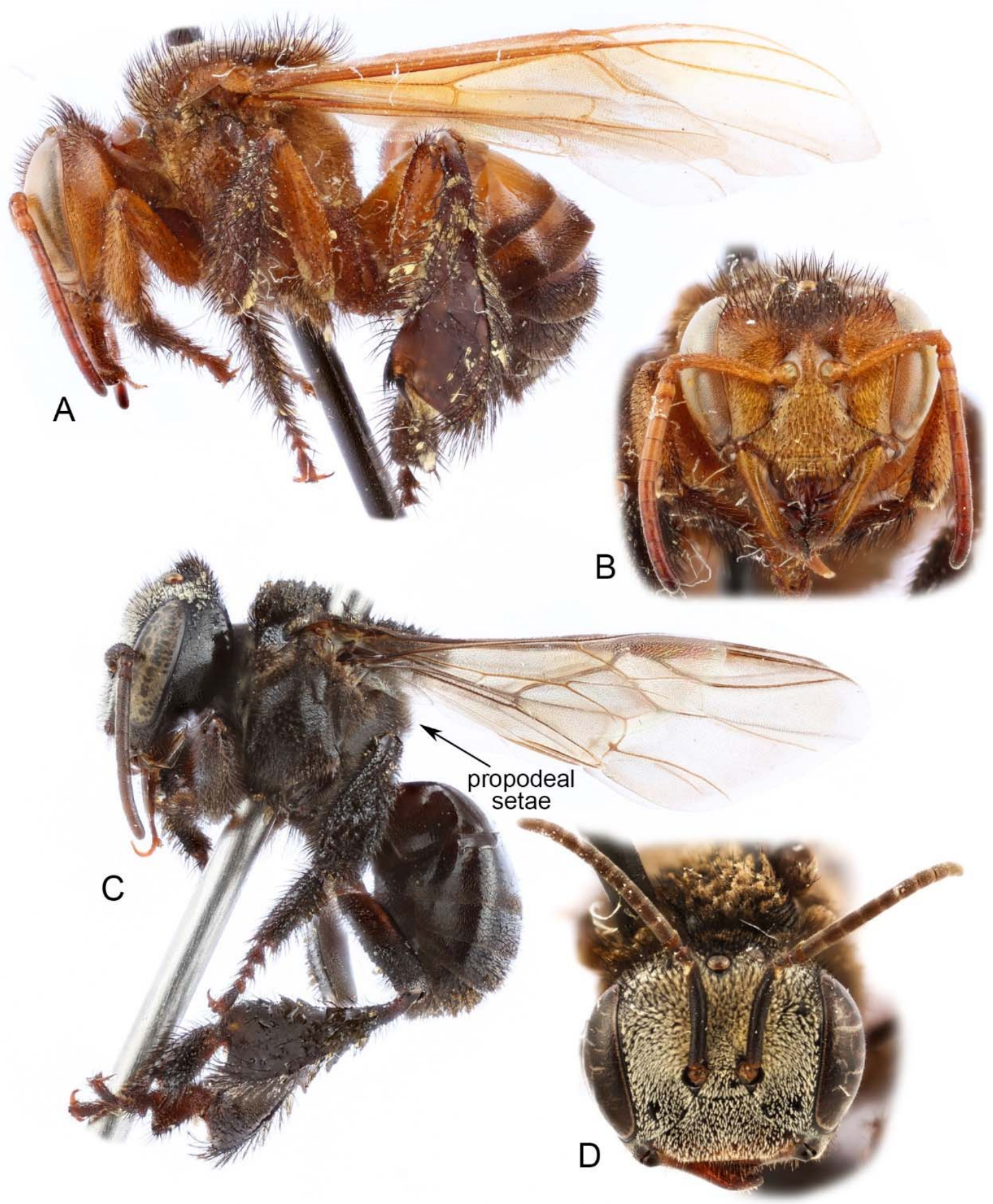

Figure 10. Morphological details of workers of Homotrigona Moure. A. Lateral habitus of Homotrigona (Homotrigona) fimbriata (Smith). B. Facial view of $H$. (H.) fimbriata. C. Lateral habitus of H. (Lophotrigona) canifrons (Smith). D. Facial view of $H$. (L.) canifrons. 


\section{Key to Subgenera of Tetragonula}

1. Scape shorter than torulocellar distance; about five distal hamuli; posterior contour of metatibia slightly convex (Fig. 11A), with distal angle subangulate; penicillus usually composed of soft setae (Sumatra, Java, Timor, Kalimantan, Sulawesi, Ambon, Maluku, Irian Jaya) Tetragonula Moure, s.str.

- Scape at least as long as torulocellar distance; six distal hamuli; posterior contour of metatibia distinctly convex (Fig. 11B) and distal angle rounded almost without angulation; penicillus composed of stiff setae (Sumatra, Kalimantan)..... Tetragonilla Moure

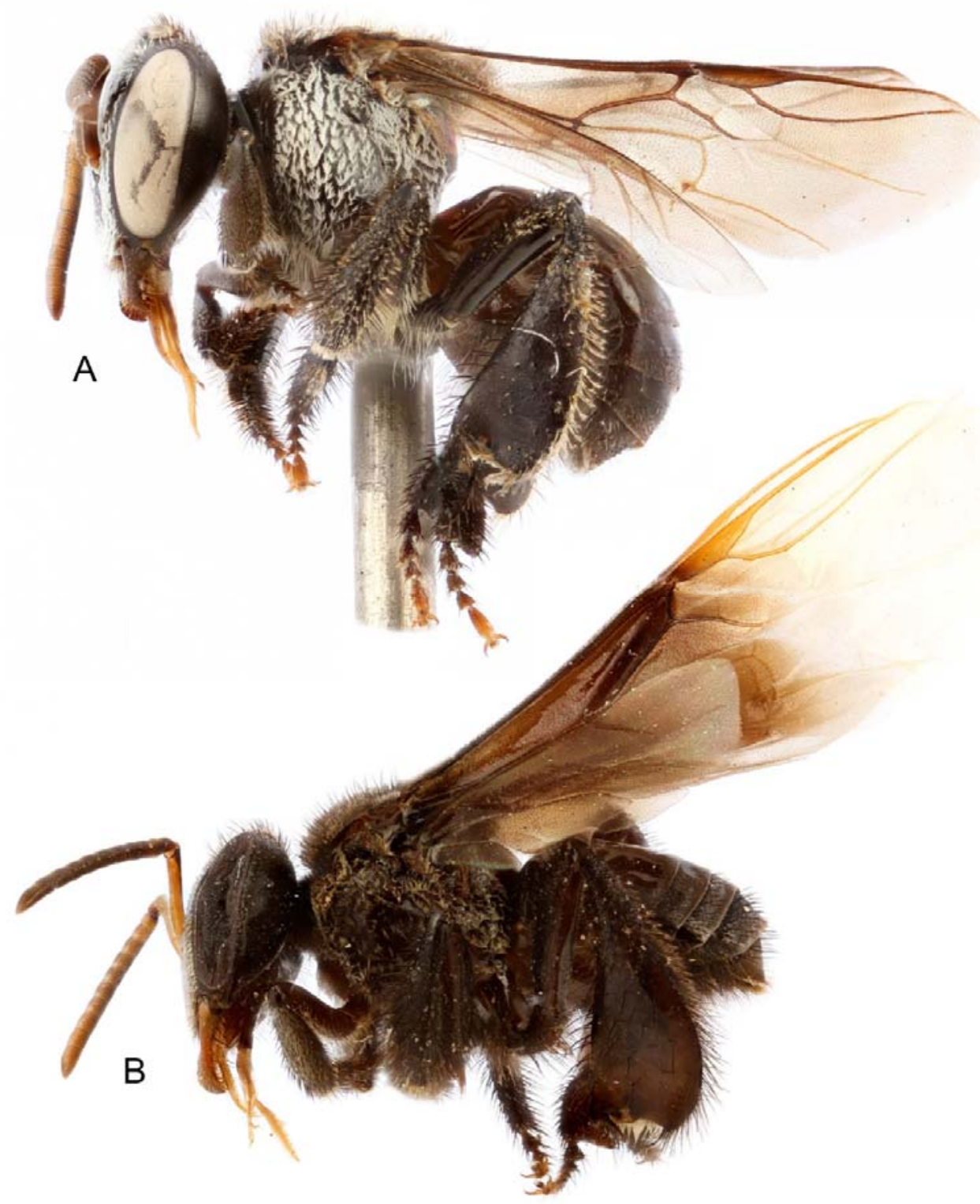

Figure 11. Lateral habitus of workers of Tetragonula Moure. A. Tetragonula (Tetragonula) hockingsi (Cockerell). B. T. (Tetragonilla) collina (Smith). 


\section{DISCUSSION}

The greatest diversity of stingless bees in Asia is concentrated across Indonesia (Kahono et al., 2018), and yet their study within the country remains to be more fully developed, particularly in terms of the implementation of sustainable systems of meliponiculture. Efforts are underway to inform and educate beekeepers about best practices which are of both economic and conservation benefits (Kahono pers. obs.), but are somewhat hampered by the lack of more extensive systematic and natural history work on the numerous species. Distributional information outside of western Indonesia is scant, with many lacunae for the various taxa, and the nesting biology, nest architecture, immature stages, and floral associations of many species remains to be documented in the literature, much of which is a necessary foundation for more extensively developing management practices. Thus, we encourage extensive surveys for bees (including the numerous other bee lineages) across Indonesia, research into the nesting biology of these species, and the gradual development of monographs to the various species of each genus and where they occur throughout the country. Indonesia bridges the extremes of the Southeast Asian and Papuasian faunas and aside from its own unique biota shares many species with these western and eastern extremes (Rasmussen, 2008). With its considerable diversity, Indonesia is poised to have a robust industry in meliponiculture and the tools for such are ripe for development.

\section{ACKNOWLEDGMENTS}

M.S.E. is grateful to the Entomological Museum Development Fund at the University of Kansas's Biodiversity Institute for support of his visit to the Museum Zoologicum Bogoriense. We are thankful to Claus Rasmussen and the anonymous reviewers for their critical reviews of the manuscript which served to improve the published version. This is a contribution of the Division of Entomology, University of Kansas Natural History Museum.

\section{REFERENCES}

Ayala, R., Gonzalez, V.H. \& Engel, M.S. 2013. Mexican stingless bees (Hymenoptera: Apidae): Diversity, distribution, and indigenous knowledge. In P. Vit, S.R.M. Pedro \& D.W. Roubik, eds. Pot-Honey: A Legacy of Stingless Bees. Springer Verlag: 135-152.

Cortopassi-Laurino, M., Imperatriz-Fonseca, V.L., Roubik, D.W., Dollin, A., Heard, T., Aguilar, I., Venturieri, G.C., Eardley, C. \& Nogueiro-Neto, P. 2006. Global meliponiculture: Challenges and opportunities. Apidologie, 37(2): 275-292.

Engel, M.S. 1999. The taxonomy of recent and fossil honey bees (Hymenoptera: Apidae: Apis). Journal of Hymenoptera Research, 8(2): 165-196. 
Engel, M.S. 2001. A monograph of the Baltic amber bees and evolution of the Apoidea (Hymenoptera). Bulletin of the American Museum of Natural History, 259: 1-192.

Engel, M.S. 2012. The honey bees of Indonesia (Hymenoptera: Apidae). Treubia, 39: 41-49.

Engel, M.S. \& Rasmussen, C. 2017. A new subgenus of Heterotrigona from New Guinea (Hymenoptera: Apidae). Journal of Melittology, 73: 1-16.

Heard, T. 2016. The Australian Native Bee Book: Keeping Stingless Bee Hives for Pets, Pollination and Sugarbag Honey. Queensland: Sugarbag Bees: 246 pp.

Kahono, S., Chantawannakul, P. \& Engel, M.S. 2018. Social bees and the current status of beekeeping in Indonesia. In P. Chantawannakul, G. Williams \& P. Neumann, eds. Asian Beekeeping in the $21^{\text {st }}$ Century. Springer Verlag: 287-306.

Mason, W.R.M. 1986. Standard drawing conventions and definitions for venational and other features of wings of Hymenoptera. Proceedings of the Entomological Society of Washington, 88(1): 1-7.

Michener, C.D. 2007. The Bees of the World. $2^{\text {nd }}$ ed. Johns Hopkins University Press.

Nogueiro-Neto, P. 1953. A Criação de Abelhas Indígenas sem Ferrão (Meliponinae). Chácaras e Quintais.

Radloff, S.E., Hepburn, H.R. \& Engel, M.S. 2011. The Asian species of Apis. In H.R. Hepburn \& S.E. Radloff, eds. Honeybees of Asia. Springer Verlag: 1-22.

Rasmussen, C. 2008. Catalog of the Indo-Malayan / Australasian stingless bees (Hymenoptera: Apidae: Meliponini). Zootaxa, 1935: 1-80.

Rasmussen, C., Thomas, J.C. \& Engel, M.S. 2017. A new genus of Eastern Hemisphere stingless bees (Hymenoptera: Apidae), with a key to the supraspecific groups of Indomalayan and Australasian Meliponini. American Museum Novitates, 3888: 1-33.

Shorthouse, D.P. 2010. SimpleMappr, an online tool to produce publication-quality point maps [program and documentation]. www.simplemappr.net. 